\title{
Effects of Temperature on the Raman Spectra and Dispersed Oxides
}

\author{
Shuibo Xie, Enrique Iglesia,* and Alexis T. Bell* \\ Chemical and Materials Sciences Divisions, Lawrence Berkeley National Laboratory, and Department of \\ Chemical Engineering, University of California, Berkeley, California 94720-1462
}

Received: December 7, 2000; In Final Form: March 6, 2001

\begin{abstract}
An investigation has been conducted of the effects of temperature on the intensities and positions of Raman bands of bulk and supported metal oxides. The relationship of band intensity to optical absorption of the sample at frequencies close to that of the laser used for Raman spectroscopy was also investigated. It was observed that bulk oxides exhibit an increase in optical absorption with increasing temperature due to a loss of oxygen and the consequent formation of nonstoichiometric oxides and stoichiometric suboxides. When the increase in optical absorption is significant at or near the frequency of the laser used for Raman spectroscopy, this gives rise to a loss in Raman signal intensity due to a decrease in the sampling depth. The closer the absorption band edge of the oxide is to the laser frequency and the weaker the metal-oxygen bond in the oxide, the more severe will be the effects of temperature on the intensity of the Raman spectrum. For dispersed metal oxides, the influence of temperature on Raman band intensity becomes less severe as the volume fraction of oxide lowers. Temperature also affects the position of the Raman bands for both bulk and supported metal oxides. With increasing temperature, all Raman bands shift to lower frequencies. This effect is attributable to thermal expansion and changes in the population of the vibrational energy levels with increasing temperature.
\end{abstract}

\section{Introduction}

In situ Raman spectroscopy is a highly effective technique for characterizing phase transformations of bulk oxides and structural transformations occurring in dispersed oxides. ${ }^{1-6}$ The technique has also been used to study the structure of adsorbed species and their transformations under reaction conditions. In the course of such investigations, it has been observed that the bands associated with bulk and dispersed oxides change in intensity in different ways with differing sample temperatures. For example, in studies of titania-supported vanadia, it has been noted that the peaks for $\mathrm{V}_{2} \mathrm{O}_{5}$ crystallites decrease in intensity and broaden with increasing sample temperature upon heating in oxygen. ${ }^{7,8}$ The authors attribute this effect to thermal broadening caused by a change in the density of states. By contrast, the intensity of the band for isolated vanadate species is not affected by temperature. ${ }^{9}$ Similar effects of temperature on Raman band intensities have been reported recently in a study of silica-supported vanadia, where it was also observed that the positions of all bands shift to lower frequency with increasing sample temperature. ${ }^{10} \mathrm{~A}$ further finding of this work is that upon lowering of the sample temperature to room temperature, all band positions return back to where they had been originally observed and the intensities of the peaks for $\mathrm{V}_{2} \mathrm{O}_{5}$ are regained. Changes in the relative intensity of bands upon changing laser intensity have been reported as well. ${ }^{11-13}$ For example, in the case of titania-supported vanadia, the intensity of the band for isolated monovanadate species was found to increase with increasing laser power, whereas that for crystallites of $\mathrm{V}_{2} \mathrm{O}_{5}$ decreased. ${ }^{13}$

* To whom correspondence should be sent. E-mail: E.Iglesia@ cchem.berkeley.edu; A. T. B., bell@cchem.berkeley.edu.
No satisfactory explanation has been given for why elevated temperatures cause the Raman bands for $\mathrm{V}_{2} \mathrm{O}_{5}$ in the spectrum of dispersed vandia to undergo changes in both position and intensity, whereas the band for monovanadate shifts only in position. Likewise, to the best of our knowledge, the effects of temperature on the Raman spectrum of oxides other than vanadia have not been explored. Because it is generally known that oxides can develop anionic vacancies at elevated temperatures and that such vacancies can increase the optical absorbance of the oxide, it was decided to investigate the effects of temperature on Raman band intensities for both bulk and dispersed oxides and to relate these observations to changes in the optical absorbance of the sample. The bulk oxides investigated were $\mathrm{V}_{2} \mathrm{O}_{5}, \mathrm{WO}_{3}, \mathrm{MoO}_{3}$, and $\mathrm{Nb}_{2} \mathrm{O}_{5}$. Silica-supported $\mathrm{V}_{2} \mathrm{O}_{5}$ was examined as a representative dispersed oxide.

\section{Experimental Section}

Bulk oxides were obtained from the following sources: $\mathrm{V}_{2} \mathrm{O}_{5}$ (Alfa Aesar, 99.995\%), $\mathrm{MoO}_{3}$ (Alfa Aesar, Puratronic, 99.9995\%), $\mathrm{WO}_{3}$ (Fisher, 99.9+\%), and $\mathrm{Nb}_{2} \mathrm{O}_{5}$ (Johnson Matthey Electronic, $99.9+\%)$. A sample of $12 \mathrm{wt} \% \mathrm{~V}_{2} \mathrm{O}_{5} / \mathrm{SiO}_{2}$ was prepared by incipient wetness impregnation of Cabosil EH- $5 \mathrm{SiO}_{2}$ with an aqueous solution of $\mathrm{NH}_{4} \mathrm{VO}_{3} .{ }^{10}$ Prior to use, the impregnated sample was dried and then heated in air at $773 \mathrm{~K}$ for $2 \mathrm{~h}$.

Raman spectra were recorded using a HoloLab series 5000 Raman spectrometer (Kaiser Optical) equipped with a Nd:YAG laser that is frequency-doubled to $532 \mathrm{~nm}$. The laser was operated at a power level of $30 \mathrm{~mW}$ measured at the sample with a power meter (Edmund Scientific). The resolution of the spectrometer is $5 \mathrm{~cm}^{-1}$. Samples $(50 \mathrm{mg})$ were pressed into 9 $\mathrm{mm}$ diameter wafers at $350 \mathrm{Mpa}$ and placed onto a rotating sample holder located within a quartz cell. To reduce laser 

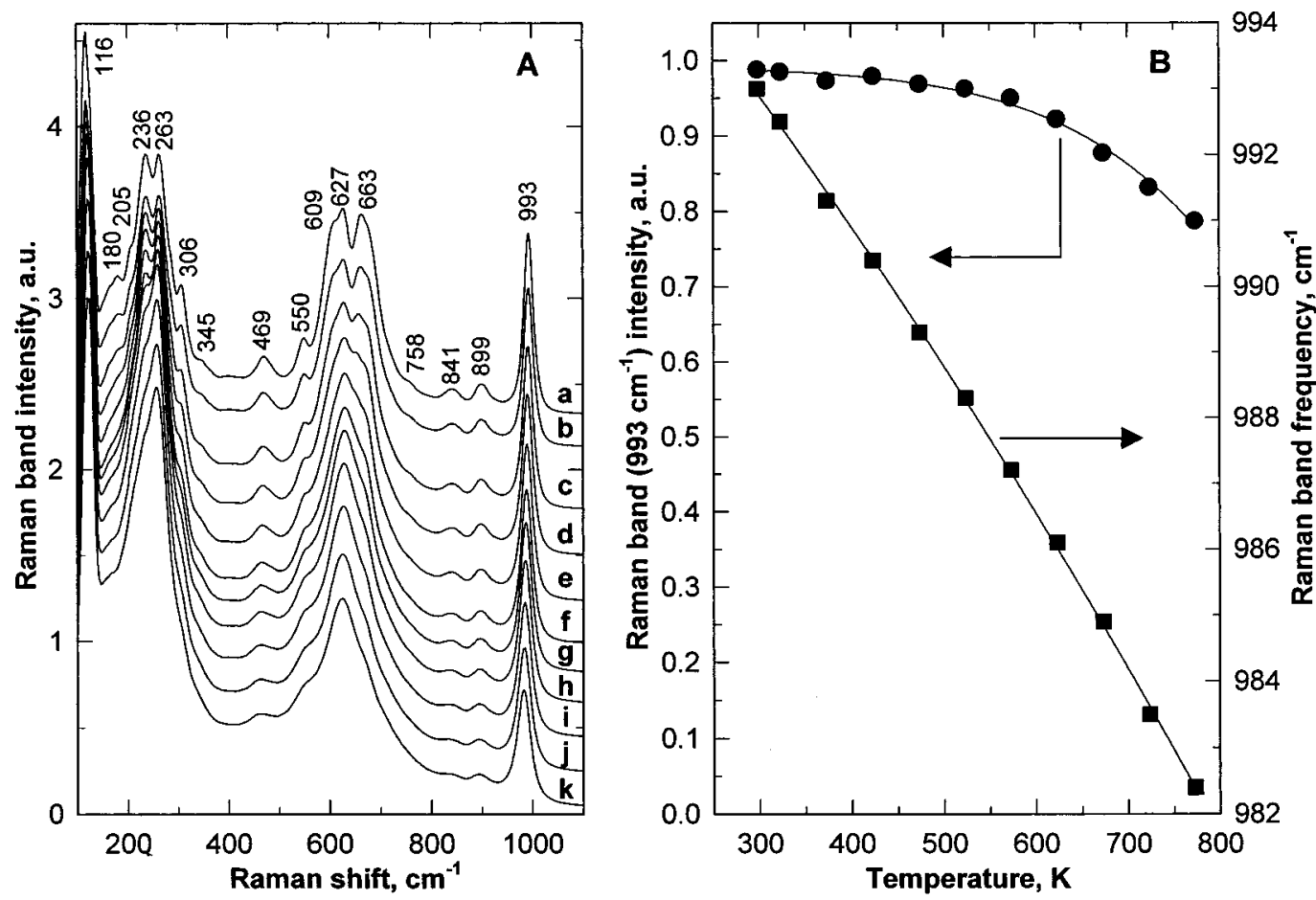

Figure 1. (A) Raman spectra of $\mathrm{Nb}_{2} \mathrm{O}_{5}$ recorded at different temperatures: (a) $298 \mathrm{~K}$; (b) $323 \mathrm{~K}$; (c) $373 \mathrm{~K}$; (d) $423 \mathrm{~K}$; (e) $473 \mathrm{~K}$; (f) $523 \mathrm{~K}$; (g) $573 \mathrm{~K}$; (h) $623 \mathrm{~K}$; (i) $673 \mathrm{~K}$; (j) $723 \mathrm{~K}$; (k) $773 \mathrm{~K}$; and (B) Dependence of the band intensity and frequency for $\mathrm{Nb}=\mathrm{O}$ stretching vibrations on temperature: $\bullet$, band intensity; $\mathbf{\square}$, band frequency.

heating, the samples were rotated at $20 \mathrm{~Hz}$. All samples were pretreated for $0.5 \mathrm{~h}$ at $723 \mathrm{~K}$ in a mixture of $20 \% \mathrm{O}_{2}$ in $\mathrm{He}$ (Scott Specialty Gases) flowing at $40 \mathrm{~cm}^{3} / \mathrm{min}$ through the Raman cell. A furnace wound onto the exterior of the Raman cell was used to heat the sample up temperatures of $773 \mathrm{~K}$.

Diffuse reflectance UV-vis spectra were recorded using a Varian-Cary 4 spectrometer equipped with a Harrick diffusereflectance cell. Magnesium oxide (Fisher, light) was used as a reference and spectra were recorded in the range of 1.5-6.0 $\mathrm{eV}$ at temperatures between 298 and $773 \mathrm{~K}$. Reflectance measurements were converted to absorption spectra suing the Kubelka-Munk function $F\left(R_{\infty}\right)$. The absorption edge energy was defined as the intercept with the abscissa of the straight line describing the near-edge region for spectra plotted as $\left[F\left(R_{\infty}\right) h v\right]^{2 / 3}$ vs $h v$, where $h v$ is the energy of the incident photon.

\section{Results}

Raman spectra of bulk $\mathrm{Nb}_{2} \mathrm{O}_{5}$ recorded at temperatures between 298 and $773 \mathrm{~K}$ are presented in Figure 1A. All of the features seen are characteristic of crystalline $\mathrm{H}-\mathrm{Nb}_{2} \mathrm{O}_{5} \cdot{ }^{14,15} \mathrm{As}$ seen in Figure 1B, there is a modest decrease in the intensity of the band at $993 \mathrm{~cm}^{-1}$ for $\mathrm{Nb}=\mathrm{O}$ vibrations as the acquisition temperature increases, and Figure $1 \mathrm{~B}$ also shows that the position of this line shifts to lower frequencies. Similar trends were observed for all of the features in the spectrum. Above $423 \mathrm{~K}, \mathrm{H}-\mathrm{Nb}_{2} \mathrm{O}_{5}$ undergoes a phase transition to the $\mathrm{T}$ - and TT-phases, as evidenced by the disappearance of the peaks at 663 and $627 \mathrm{~cm}^{-1}$, and the appearance of the peak at 692 $\mathrm{cm}^{-1} \cdot{ }^{15,16}$

$\mathrm{UV}-$ vis spectra of $\mathrm{Nb}_{2} \mathrm{O}_{5}$ are shown in Figure $2 \mathrm{~A}$ as a function of temperature. At $298 \mathrm{~K}$, the absorption band edge, $E$, is located at $3.10 \mathrm{eV}$. As the temperature increases, the value of $F\left(R_{\infty}\right)$ increases, and the value of $E_{\mathrm{g}}$ decreases. The dependence of the absorption band edge on temperature can be described by the empirical expression $E_{\mathrm{g}}=E_{\mathrm{g} 0}+a T$, where
$E_{\mathrm{g} 0}$ is the absorption band edge at $0 \mathrm{~K}$, and $a$ is the temperature sensitivity of the absorption band edge. Values for $E_{\mathrm{g} 0}$ and a are listed in Table 1. The vertical lines in Figure 3A are placed at the frequencies of the laser line used for Raman spectroscopy (532 nm or $18797 \mathrm{~cm}^{-1}$ ) and the frequency of the scattered light corresponding to the Raman band at $993 \mathrm{~cm}^{-1}$ (19 780 $\left.\mathrm{cm}^{-1}\right)$. The change in $F\left(R_{\infty}\right)$ at both of these frequencies with temperature is identical, as can be seen from Figure 2B.

Results similar to those presented for $\mathrm{Nb}_{2} \mathrm{O}_{5}$ are presented in Figures 3 and 4 for bulk $\mathrm{MoO}_{3}$, in Figures 5 and 6 for bulk $\mathrm{WO}_{3}$, and in Figures 7 and 8 for bulk $\mathrm{V}_{2} \mathrm{O}_{5}$. The positions of each band are listed in the figures. The positions of these bands are in excellent agreement with previous studies of the bulk phases of $\mathrm{MoO}_{3},{ }^{17,18} \mathrm{WO}_{3},{ }^{19,20}$ and $\mathrm{V}_{2} \mathrm{O}_{5} \cdot{ }^{21}$ For each of the oxides investigated, the intensity of the Raman signal decreases with increasing temperature, and the degree of optical absorption increases. As noted in Table 1, the absorption-band edge decreases with temperature for all of the oxides in a manner identical to that for $\mathrm{Nb}_{2} \mathrm{O}_{5}$. It is significant to note that the decreases in the intensity of the Raman band for $\mathrm{M}=\mathrm{O}$ vibrations correlates with the degree of increase in the optical absorption with increasing temperature. This trend also correlates with the proximity of the laser and Raman lines to the absorption band edge, the smaller the gap the more intense is the effect of temperature on the intensity of the Raman signal. For the oxides studied the effects of temperature on Raman signal intensity and optical absorbance at the frequency of the laser line increase in the order $\mathrm{Nb}_{2} \mathrm{O}_{5}<\mathrm{MoO}_{3}<\mathrm{WO}_{3}<\mathrm{V}_{2} \mathrm{O}_{5}$.

Figure 9 shows the effects of temperature on Raman spectra of $12 \% \mathrm{~V}_{2} \mathrm{O}_{5} / \mathrm{SiO}_{2}$. This sample exhibits bands at 146, 198, 285, 306, 484, 527, 703, and $997 \mathrm{~cm}^{-1}$ for particles of $\mathrm{V}_{2} \mathrm{O}_{5}$, as well as a band at $1042 \mathrm{~cm}^{-1}$ for isolated monovanadate species. ${ }^{10,22}$ The shoulder at $1077 \mathrm{~cm}^{-1}$ is attributable to $\mathrm{Si}-$ $\mathrm{O}-$ species in silica produced by the formation of $\mathrm{V}-\mathrm{O}-\mathrm{Si}$ bonds. ${ }^{22}$ With increasing temperature, the bands for supported particles of $\mathrm{V}_{2} \mathrm{O}_{5}$ decrease monotonically, whereas that for 

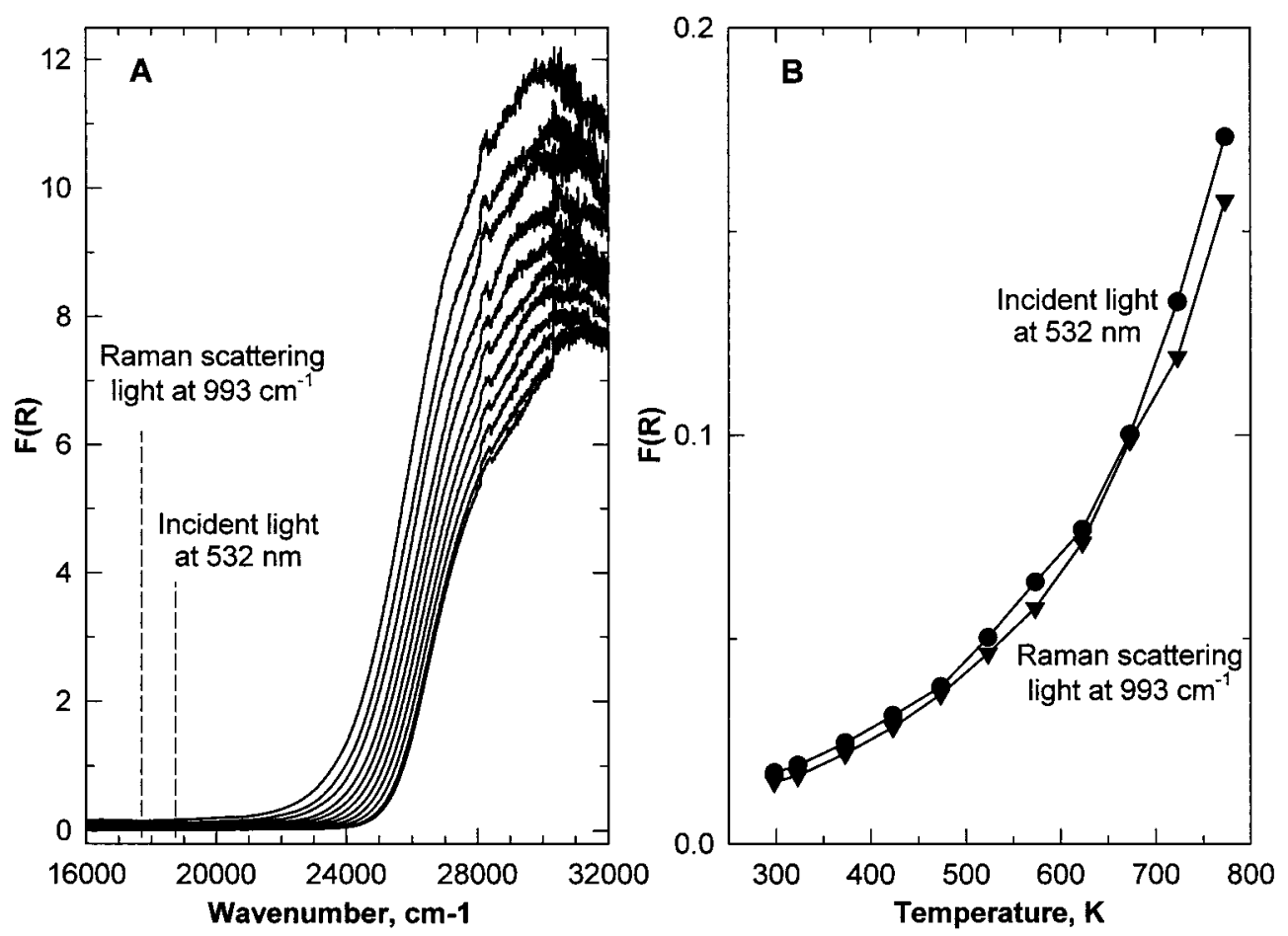

Figure 2. (A) UV-vis spectra of $\mathrm{Nb}_{2} \mathrm{O}_{5}$ recorded at different temperatures: spectra from bottom to top were recorded at 298, 323, 373, 423, 473, 523, 573, 623, 673, and $748 \mathrm{~K}$; and (B) Temperature dependence of $\mathrm{Nb}_{2} \mathrm{O}_{5}$ absorption at energies corresponding to incident laser (532 nm) and Raman scattering light at $993 \mathrm{~cm}^{-1}$ respectively $\left(18800\right.$ and $\left.17807 \mathrm{~cm}^{-1}\right)$ :

TABLE 1: Values of $E_{\mathrm{g} 0}$ and a for different oxides $^{a a} E_{\mathrm{g}}=$ $E_{\mathrm{g} 0}+a^{*} T, E_{\mathrm{g} 0}$ is the value at $0 \mathrm{~K}$

\begin{tabular}{lcc}
\hline oxides & $E_{\mathrm{g} 0}(\mathrm{eV})$ & $a(\mathrm{eV} / \mathrm{K})$ \\
\hline $\mathrm{V}_{2} \mathrm{O}_{5}$ & 2.42 & $-6.9 \times 10^{-4}$ \\
$\mathrm{WO}_{3}$ & 2.87 & $-7.7 \times 10^{-4}$ \\
$\mathrm{MoO}_{3}$ & 3.20 & $-7.2 \times 10^{-4}$ \\
$\mathrm{Nb}_{2} \mathrm{O}_{5}$ & 3.23 & $-4.5 \times 10^{-4}$
\end{tabular}

monovanadate species is not affected significantly. These trends are clearly illustrated in Figure 10A. The effects of temperature on band position are shown in Figure 10B. In this case, it is seen that with increasing temperature there is a downward shift in the frequencies for $\mathrm{V}=\mathrm{O}$ vibrations in both $\mathrm{V}_{2} \mathrm{O}_{5}$ and isolated monovanadate species. Effects similar to those shown in Figure $10 \mathrm{~A}$ and $10 \mathrm{~B}$ were obtained if the sample was maintained at room temperature but was not rotated. On the basis of the decrease in the intensity of the band at $993 \mathrm{~cm}^{-1}$ for $\mathrm{V}_{2} \mathrm{O}_{5}$, it was estimated that the temperature of the sample illuminated by the laser was $598 \mathrm{~K}$. This result demonstrates very clearly the importance of sample rotation in order to avoid artifacts caused by local sample heating.

In contrast to bulk $\mathrm{V}_{2} \mathrm{O}_{5}, 12 \% \mathrm{~V}_{2} \mathrm{O}_{5} / \mathrm{SiO}_{2}$ shows no evidence of optical absorption in the vicinity of the laser frequency, and the absorption band edge in the UV-vis spectrum occurs at about $25000 \mathrm{~cm}^{-1}(4.9 \mathrm{eV})$. Similar observations concerning the position of the band edge for low weight loading $\mathrm{V}_{2} \mathrm{O}_{5}$ / $\mathrm{SiO}_{2}$ have been reported in ref 22 .

\section{Discussion}

Increasing temperature has two effects on the Raman spectrum for each of the bulk oxides examined. The first is a red shift in the frequency of all lines and the second is a decrease in the intensity of the Raman bands. The magnitude of the first of these trends is essentially the same for all four oxides-a decrease in the band position of about $6 \mathrm{~cm}^{-1}$ for a temperature
Q, absorption of incident laser; $\mathbf{\nabla}$, absorption at Raman scattering light.

increase from 298 to $773 \mathrm{~K}$. This trend is well documented for solids and is usually ascribed to the effects of thermal expansion and changes in phonon occupation numbers. ${ }^{23,24}$

The effects of temperature on band intensity have also been reported, ${ }^{23-25}$ but the mechanism for such effects remains unclear. In the present study, we have shown that the decrease in the Raman intensity of bulk oxides with increasing temperature correlates with an increase in the optical absorbance of the sample at the frequencies involved in the Raman process. A similar correlation between Raman intensity and optical absorbance has been observed in solutions and has been ascribed to a decrease in the penetration depth of the laser line caused by an increase in the optical absorbance of the solution. ${ }^{5}$ If the absorbance of visible light obeys the Beer-Lambert law, then for a semiinfinite layer of liquid containing a fixed concentration of Raman scatterers, the dependence of the Raman signal intensity on the concentration of an optical absorber will have the following form

$$
I\left(v_{\mathrm{R}}\right)=I_{\mathrm{o}}\left(v_{\mathrm{R}}\right) \frac{K_{\mathrm{o}}\left(v_{\mathrm{L}}\right)+K_{\mathrm{o}}\left(v_{\mathrm{R}}\right)}{K\left(v_{\mathrm{L}}\right)+K\left(v_{\mathrm{R}}\right)}
$$

where $I\left(v_{\mathrm{R}}\right)$ and $I_{\mathrm{o}}\left(\nu_{\mathrm{R}}\right)$ are the Raman intensities at the frequency $\nu_{\mathrm{R}}$ for the sample and a reference solution, $K$ and $K_{\mathrm{o}}$ are the corresponding optical absorbances, and $v_{\mathrm{R}}$ and $v_{\mathrm{L}}$ are the frequencies of the laser line and the scattered light, respectively. If $K$ is proportional to concentration of the optical absorber, then eq 1 becomes

$$
I\left(v_{\mathrm{R}}\right)=I_{\mathrm{o}}\left(v_{\mathrm{R}}\right) \frac{C_{\mathrm{o}}}{C}
$$

where $C_{\mathrm{o}}$ and $C$ are the concentrations of the optical absorber in the reference and sample solutions, respectively. From eq 2 , it is evident that the strength of the Raman signal will decrease 

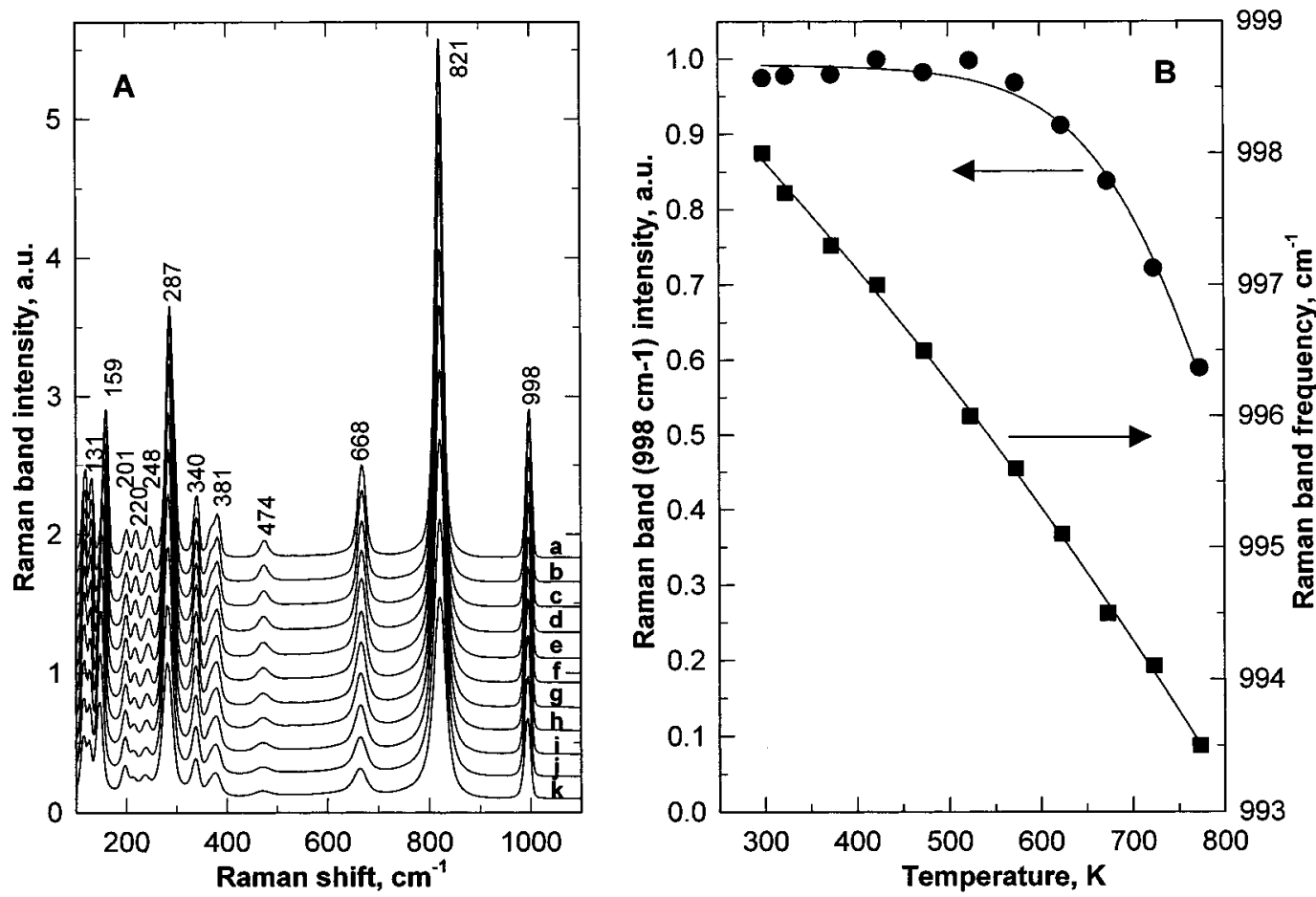

Figure 3. (A) Raman spectra of $\mathrm{MoO}_{3}$ recorded at different temperatures: (a) $298 \mathrm{~K}$; (b) $323 \mathrm{~K}$; (c) $373 \mathrm{~K}$; (d) $423 \mathrm{~K}$; (e) $473 \mathrm{~K}$; (f) $523 \mathrm{~K}$; (g) $573 \mathrm{~K}$; (h) $623 \mathrm{~K}$; (i) $673 \mathrm{~K}$; (j) $723 \mathrm{~K}$; (k) $773 \mathrm{~K}$; and (B) Dependence of the band intensity and frequency for Mo=O stretching vibrations on temperature: $\bullet$, band intensity; $\mathbf{\square}$, band frequency.
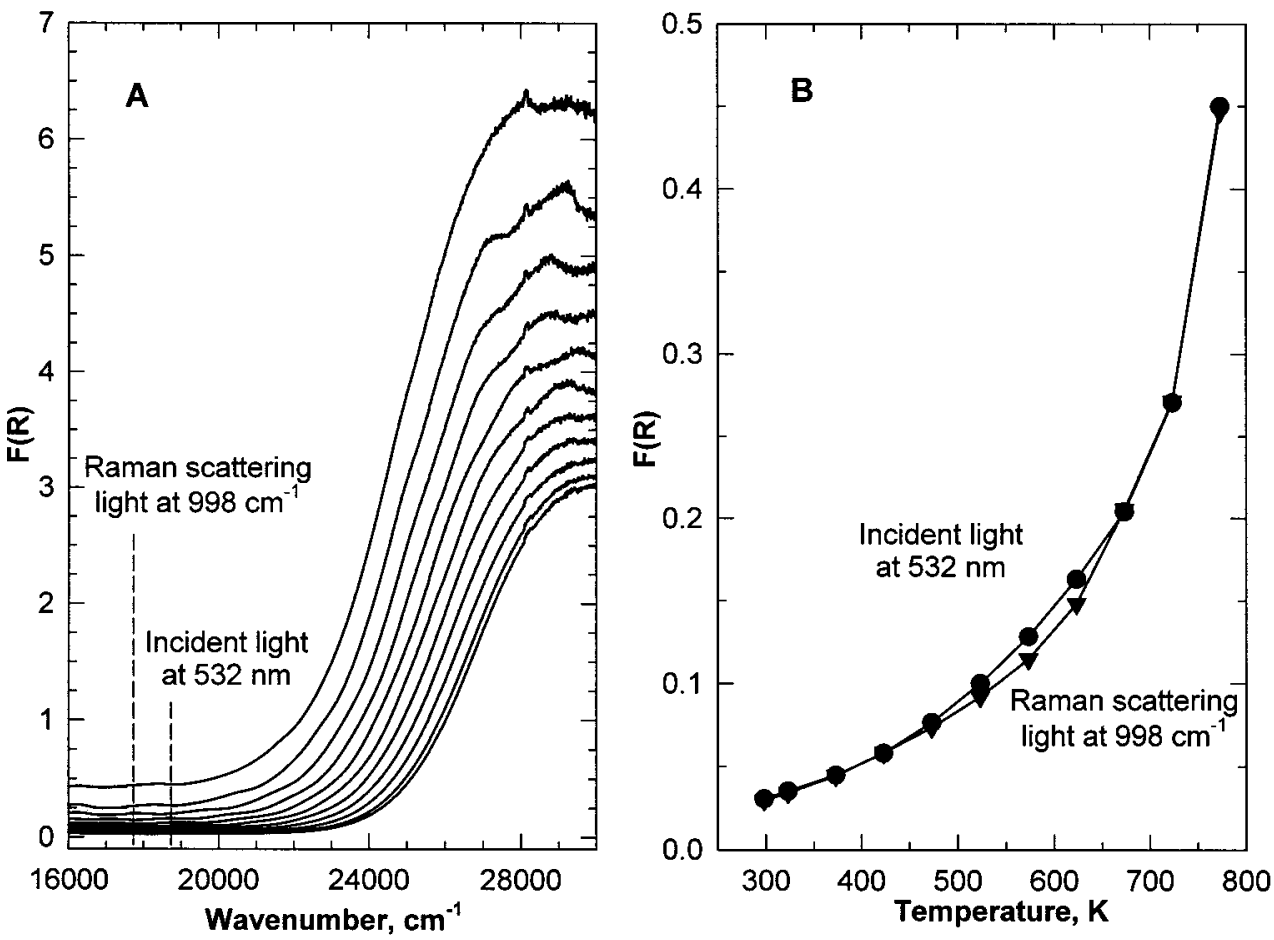

Figure 4. (A) UV-vis spectra of $\mathrm{MoO}_{3}$ recorded at different temperatures: spectra from bottom to top were recorded at 298, 323, 373, 423, 473, 523, 573, 623, 673, and $748 \mathrm{~K}$; and (B) Temperature dependence of $\mathrm{MoO}_{3}$ absorption at energies corresponding to incident laser and Raman scattering light at $998 \mathrm{~cm}^{-1}$ respectively (18 800 and $\left.17802 \mathrm{~cm}^{-1}\right)$ : $\bullet$, absorption of incident laser; $\mathbf{\nabla}$, absorption at Raman scattering light.

as the concentration of optical absorber in the sample solution increases relative to that in the reference solution.

For solids, interpretation of the effects of an increase in the optical absorbance is more complex because both scattering and absorption can occur concurrently. Although a general theory for Raman scattering from a bed of powder is not available, it seems reasonable to assume that, to a first approximation, the intensity of the scattered light should be represented by the
Kubelka-Munk relationship. ${ }^{1,26}$ For normal incidence of the laser beam on a sufficiently thick layer of powder, the ratio of the scattered to incident light is given by ${ }^{26}$

$$
I / I_{0}=\left[1+K / S+(K / S(K / S+2))^{1 / 2}\right]^{-1}
$$

where $I_{0}$ is the intensity of the incident radiation, $I$ is the intensity 

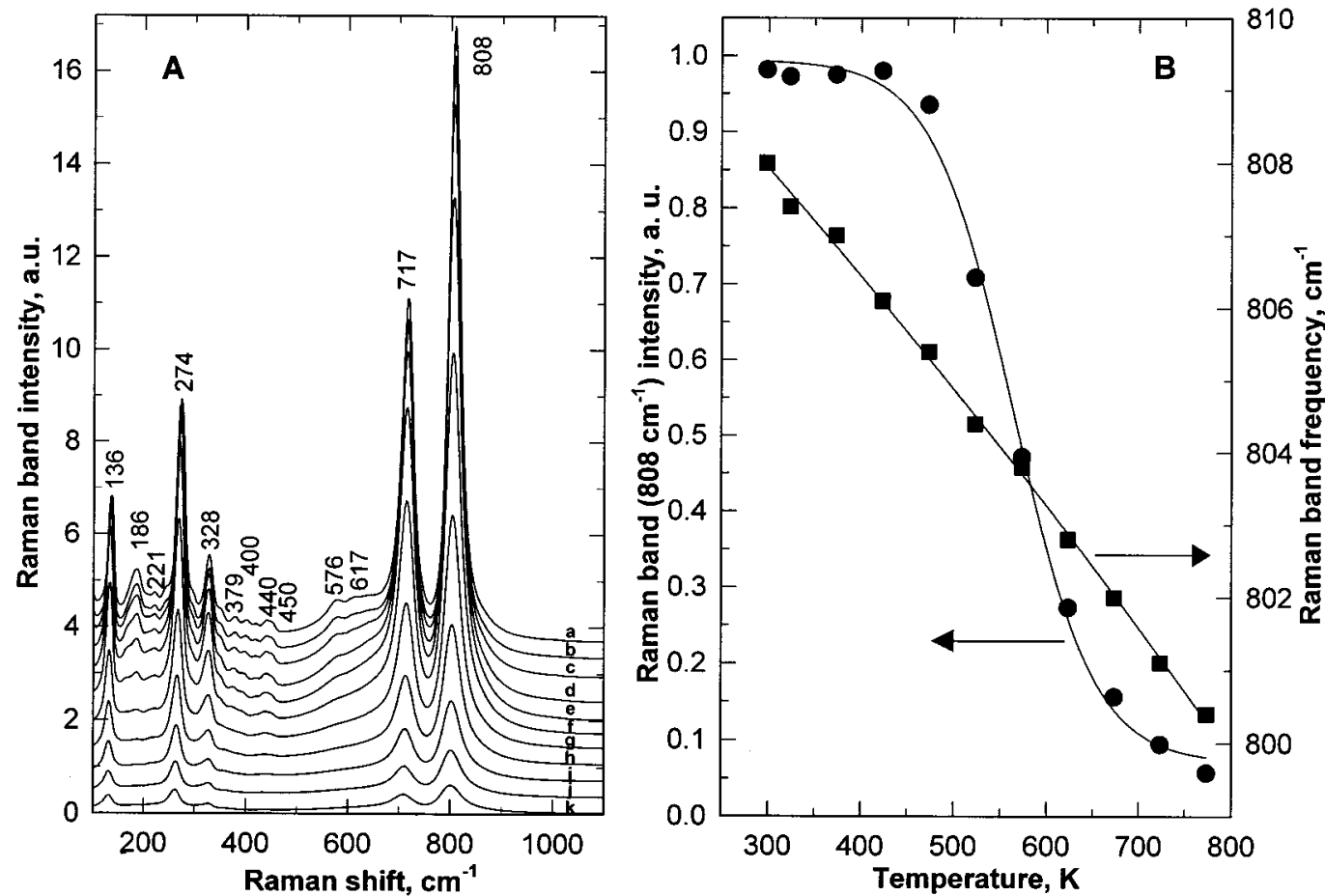

Figure 5. (A) Raman spectra of $\mathrm{WO}_{3}$ recorded at different temperatures: (a) $298 \mathrm{~K}$; (b) $323 \mathrm{~K}$; (c) $373 \mathrm{~K}$; (d) $423 \mathrm{~K}$; (e) $473 \mathrm{~K}$; (f) $523 \mathrm{~K}$; (g) $573 \mathrm{~K}$; (h) $623 \mathrm{~K}$; (i) $673 \mathrm{~K}$; (j) $723 \mathrm{~K}$; (k) $773 \mathrm{~K}$; and (B) Dependence of the band intensity and frequency for W=O stretching vibrations on temperature: $\bullet$, band intensity; $\mathbf{\square}$, band frequency.
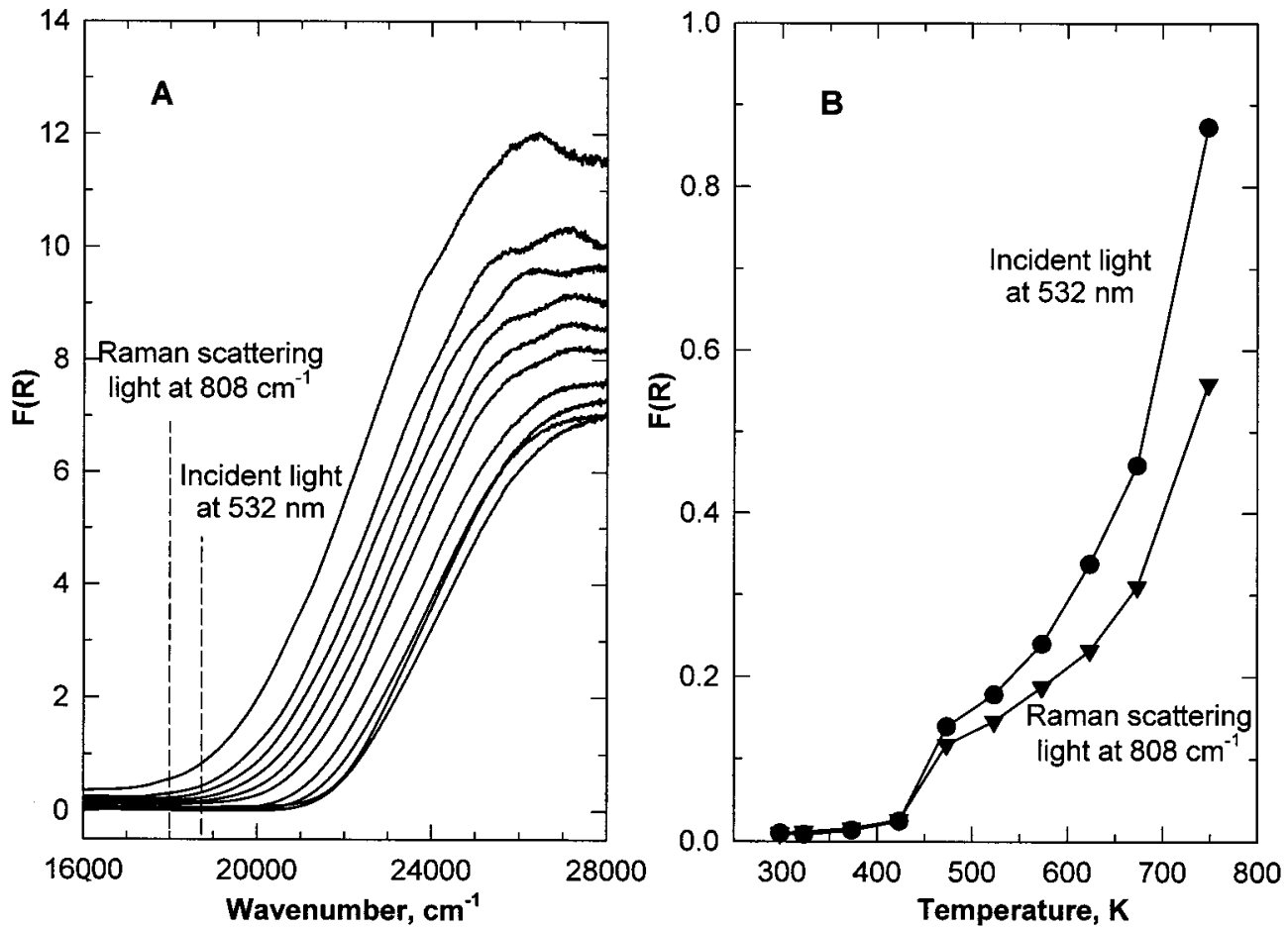

Figure 6. (A) UV-vis spectra of $\mathrm{WO}_{3}$ recorded at different temperatures: spectra from bottom to top were recorded at 298, 323, 373, 423, 473, $523,573,623,673$, and $748 \mathrm{~K}$; and (B) Temperature dependence of $\mathrm{WO}_{3}$ absorption at energies corresponding to incident laser and Raman scattering light at $808 \mathrm{~cm}^{-1}$ respectively (18 800 and $\left.17992 \mathrm{~cm}^{-1}\right)$ :

of the scattered radiation at the surface of the powder layer, $K$ is the absorption coefficient of the powder, and $S$ is the scattering coefficient. In general, $S$ will be fairly insensitive to frequency but $K$ can be a strong function of frequency, particularly if the frequency of the radiation is close to that corresponding to the absorption band edge of the solid. If we now assume that $I$ corresponds to the intensity of the Raman scattered light, $I_{R}$, then the ratio $I_{R}(T) / I_{R}(298)$ can be expressed as

$$
\begin{aligned}
& I_{\mathrm{R}}(T) / I_{\mathrm{R}}(298)= \\
& \quad \frac{\left[1+K(298) / S+(K(298) / S(K(298) / S+2))^{1 / 2}\right]^{-1}}{\left[1+K(T) / S+(K(T) / S(K(T) / S+2))^{1 / 2}\right]^{-1}}
\end{aligned}
$$

Because $K / S=F\left(R_{\infty}\right)$, the ratio $K / S$ appearing in eq 5 can be 

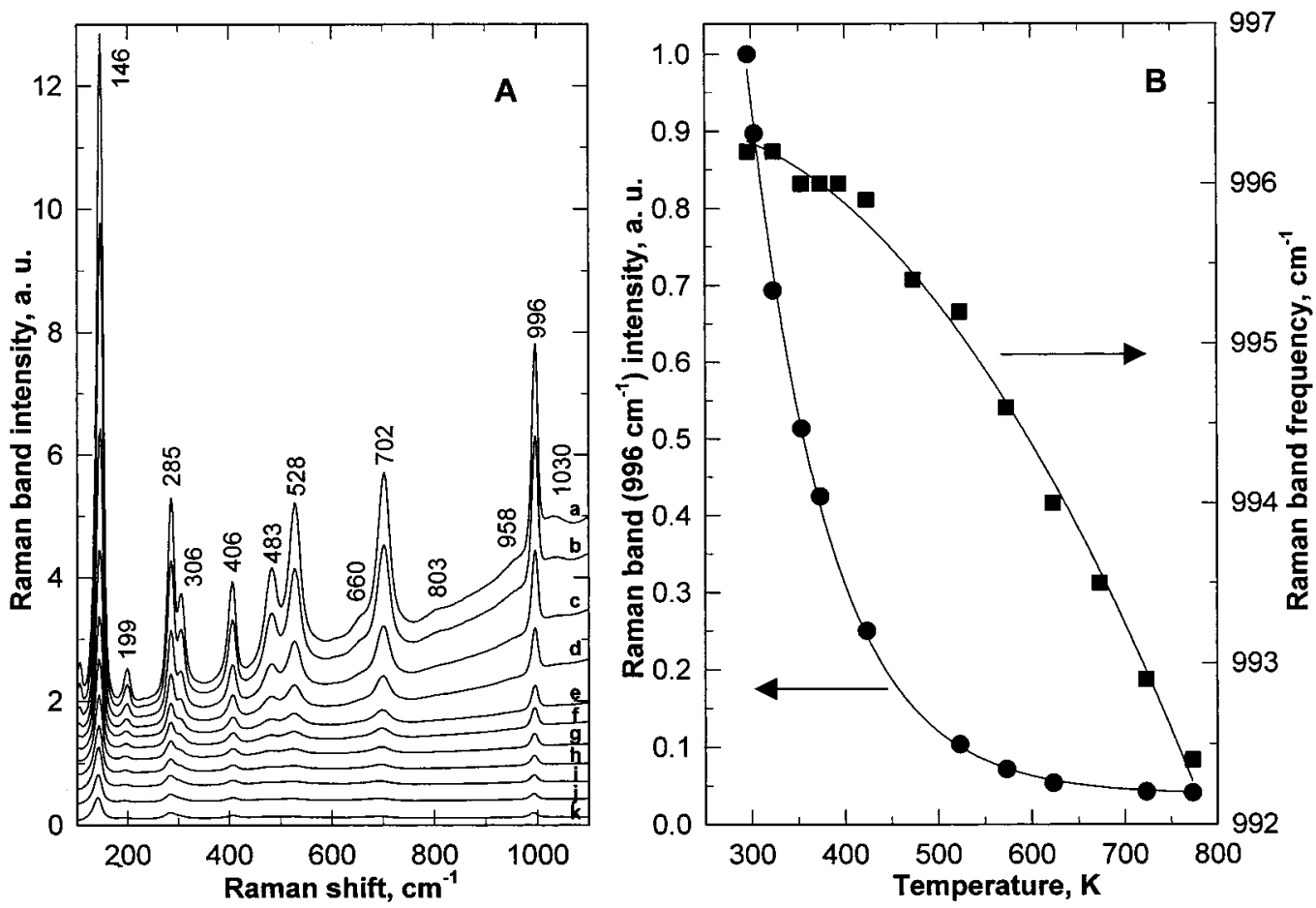

Figure 7. (A) Raman spectra of $\mathrm{V}_{2} \mathrm{O}_{5}$ recorded at different temperatures: (a) $298 \mathrm{~K}$; (b) $303 \mathrm{~K}$; (c) $323 \mathrm{~K}$; (d) $353 \mathrm{~K}$; (e) $373 \mathrm{~K}$; (f) $423 \mathrm{~K}$; (g) $523 \mathrm{~K}$; (h) $573 \mathrm{~K}$; (i) $623 \mathrm{~K}$; (j) $723 \mathrm{~K}$; (k) $773 \mathrm{~K}$; and (B) Dependence of the band intensity and frequencies for V=O stretching vibrations on temperature: $\bullet$, band intensity; $\mathbf{\square}$, band frequency.
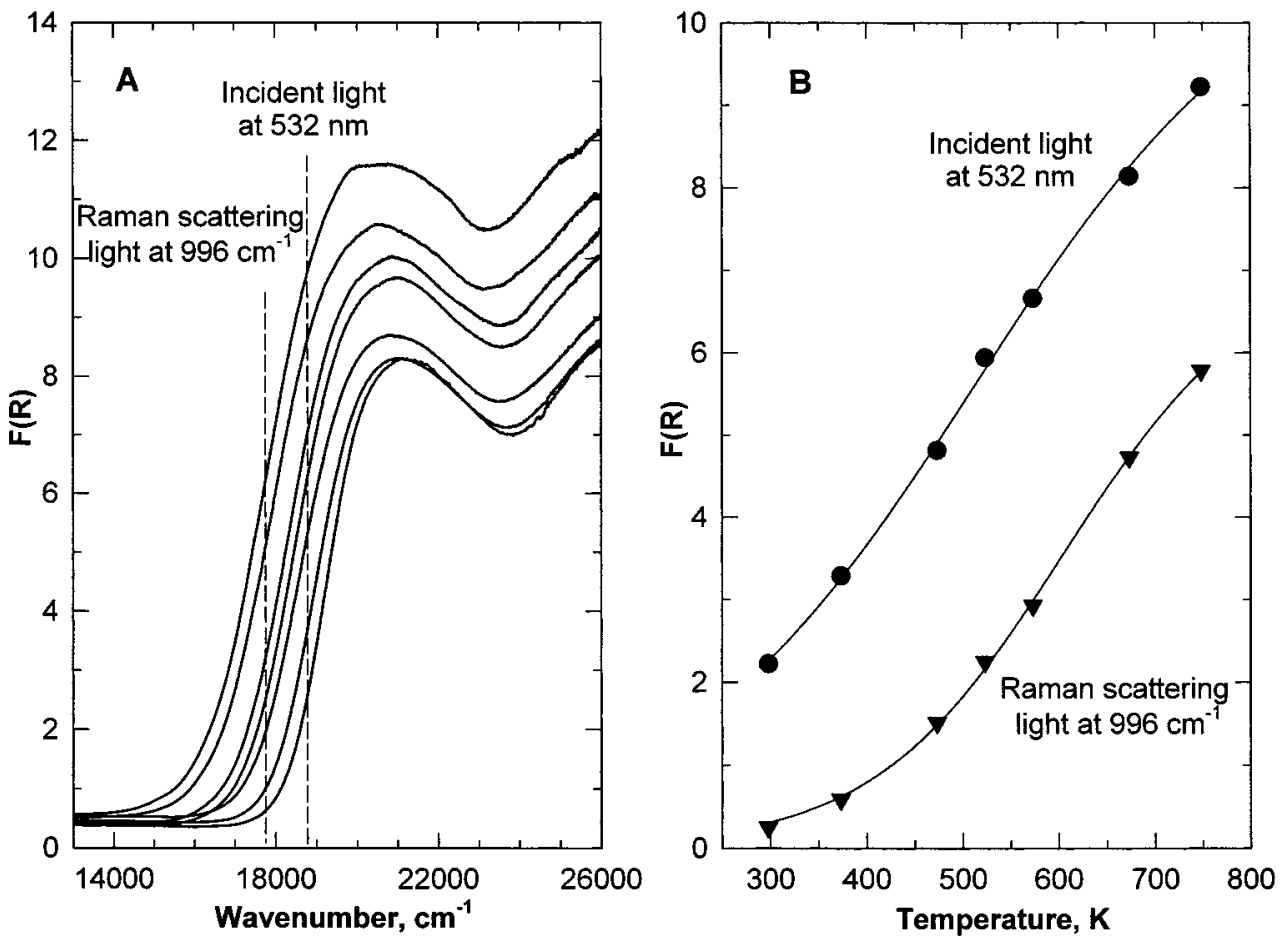

Figure 8. (A) UV-vis spectra of $\mathrm{V}_{2} \mathrm{O}_{5}$ recorded at different temperatures: spectra from bottom to top were recorded at 298, 373, 473, 523, 573, 673 , and $748 \mathrm{~K}$; and (B) Temperature dependence of $\mathrm{V}_{2} \mathrm{O}_{5}$ absorption at energies corresponding to incident laser and Raman scattering light at 996 $\mathrm{cm}^{-1}$ respectively $\left(18800\right.$ and $\left.17804 \mathrm{~cm}^{-1}\right)$ : $\mathbf{0}$, absorption of incident laser; $\mathbf{\nabla}$, absorption at Raman scattering light.

evaluated from a reading of the Kubelka-Munk function for the specified temperature. Figure 11 presents plots of $I_{R}(T) /$ $\mathrm{I}_{\mathrm{R}}(298)$ determined from eq 5 , together with the corresponding data taken from Figures $1 \mathrm{~B}, 3 \mathrm{~B}, 5 \mathrm{~B}$, and $7 \mathrm{~B}$. It is evident that eq 5 captures the effects of temperature on the intensity of the Raman band for $\mathrm{M}=\mathrm{O}$ vibrations in a qualitative fashion. For materials such as $\mathrm{Nb}_{2} \mathrm{O}_{5}$ that do not absorb radiation strongly at the optical frequency corresponding to the Raman band, eq
5 over-predicts the effect of temperature on the decrease in intensity of the Raman band. By contrast, for strongly absorbing materials such as $\mathrm{V}_{2} \mathrm{O}_{5}$, eq 5 under-predicts the effect of temperature on the intensity of the Raman band. Nevertheless, it is evident that observed decrease in Raman band intensity with increasing temperature is due to the increased optical absorbance by the oxide.

In the case of silica-supported vanadia, Figure 10 shows that 


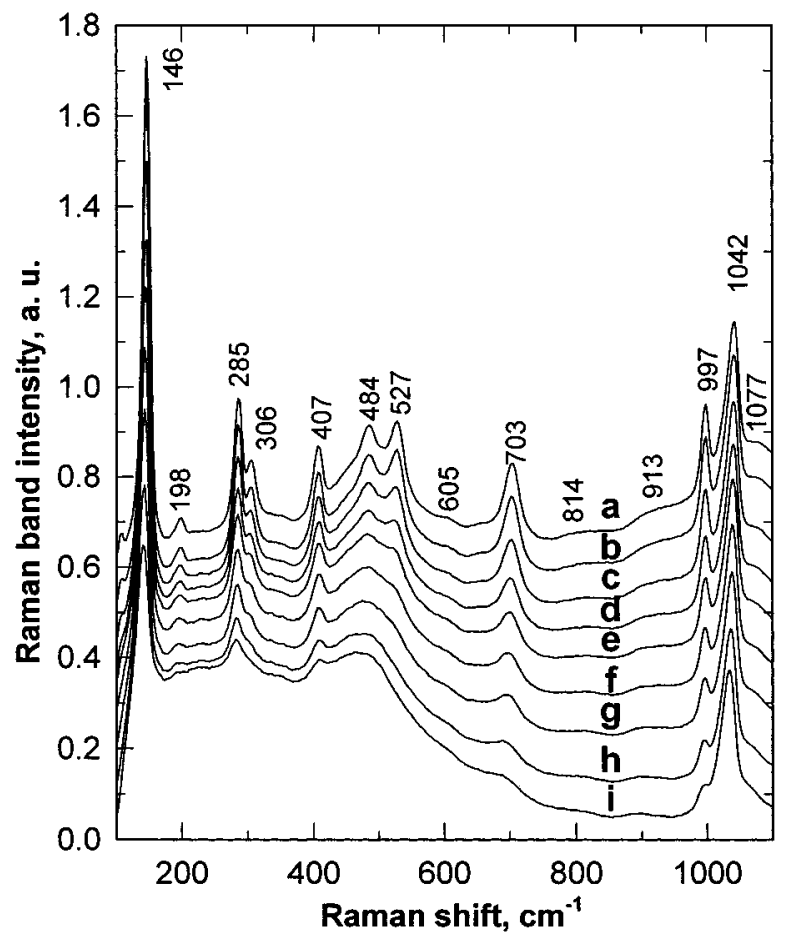

Figure 9. Raman spectra of $12 \mathrm{wt} \% \mathrm{~V}_{2} \mathrm{O}_{5} / \mathrm{SiO}_{2}$ recorded at different temperatures: (a) $298 \mathrm{~K}$; (b) $323 \mathrm{~K}$; (c) $373 \mathrm{~K}$; (d) $423 \mathrm{~K}$; (e) $473 \mathrm{~K}$; (f) $523 \mathrm{~K}$; (g) $573 \mathrm{~K}$; (h) $673 \mathrm{~K}$; and (i) $773 \mathrm{~K}$.

with increasing temperature, the intensity of the band at 1042 $\mathrm{cm}^{-1}$ for monovanadate species undergoes a very small decrease in intensity, whereas that at $997 \mathrm{~cm}^{-1}$ for crystallites of $\mathrm{V}_{2} \mathrm{O}_{5}$ decreases significantly. The fraction of vanadium present as $\mathrm{V}_{2} \mathrm{O}_{5}$ in this sample can be estimated from the relative intensities of the bands at 1042 and $997 \mathrm{~cm}^{-1}$ observed at $298 \mathrm{~K}$ and the relative Raman scattering cross sections for these two species. In previous work, we have estimated that the scattering cross section for $\mathrm{V}_{2} \mathrm{O}_{5}$ is about 10 times that for monovanadate species. ${ }^{10}$ Therefore, only $5 \%$ of the vanadium present in the $12 \% \mathrm{~V}_{2} \mathrm{O}_{5} / \mathrm{SiO}_{2}$ sample is crystalline $\mathrm{V}_{2} \mathrm{O}_{5}$. Because the absorption band edge for this sample occurs at a frequency much higher than that of the laser line and the Raman scattered radiation, the value of $K / S$ is very small at these frequencies and, consequently, the ratio of scattered to incident radiation (eq 5) is essentially unity. This means that Raman scattering from all parts of the sample will be observable and not just that generated near the upper portions. Previous studies have shown that isolated monovanadate species exhibit optical absorbances below $350 \mathrm{~nm}\left(28571 \mathrm{~cm}^{-1}\right)^{27-29}$ and that the model compound $\mathrm{O}=\mathrm{V}\left[\mathrm{SiO}\left(\mathrm{O}^{t} \mathrm{Bu}\right)_{3}\right]_{3}$ exhibits an $\mathrm{O} \rightarrow \mathrm{V}$ ligandto-metal charge-transfer band at at $250 \mathrm{~nm}\left(40000 \mathrm{~cm}^{-1}\right) .30$ As a consequence, isolated monovanadate species do not absorb radiation near the frequency of the laser line $532 \mathrm{~nm}$, and therefore, all of the monovanadate species should be observable. Because the optical absorbance of the sample does not change with increasing temperature in the frequency domain of the laser line and the Raman scattered radiation, there should be no change in the intensity of the Raman band at $1042 \mathrm{~cm}^{-1}$ for monovanadate, consistent with what is observed. By contrast, the small particles of $\mathrm{V}_{2} \mathrm{O}_{5}$ have an absorption band edge in the vicinity of the laser line (see Figure 7). It is proposed that the decrease in the intensity of the Raman band at $997 \mathrm{~cm}^{-1}$ for the crystallites of $\mathrm{V}_{2} \mathrm{O}_{5}$ observed as the sample temperature increases is caused by absorption of the Raman scattered photons within the crystallites. Thus, only a fraction of the Raman scattered photons generated within a given crystallite leave the crystallite, and with increasing strength of absorption, this fraction decreases. Therefore, the interpretation of the effects of temperature for silica-supported vanadia differs from that given for bulk $\mathrm{V}_{2} \mathrm{O}_{5}$, for which it is proposed that the decrease in Raman band intensity is due to a decrease in the fraction of the sample from which the Raman signal is generated. Although optical absorption near the laser frequency is responsible for the loss in Raman signal intensity in both cases, this loss is attributed to sampling depth effects for bulk oxides and to
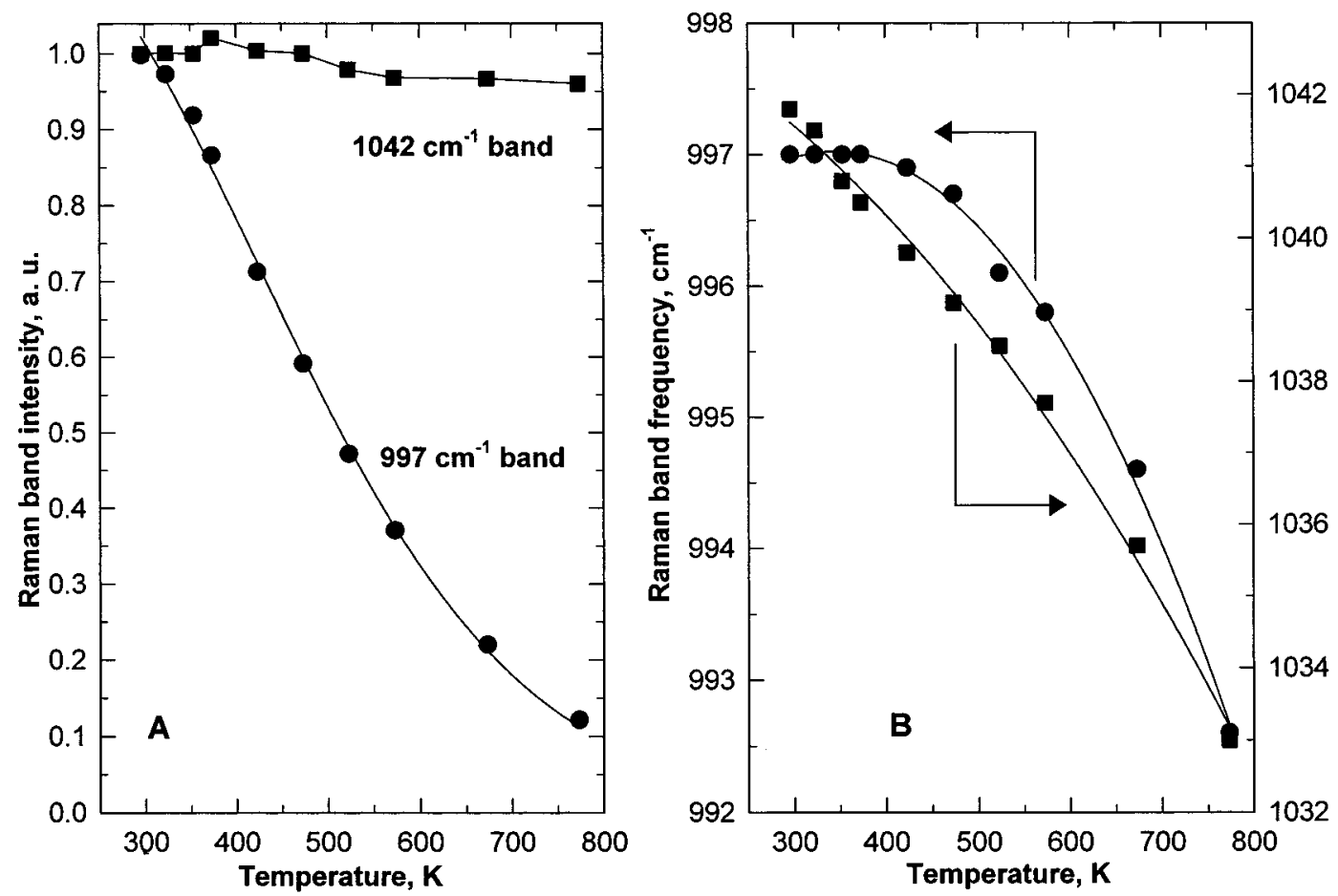

Figure 10. Temperature dependence of the band intensity (A) and frequency (B) for $\mathrm{V}=\mathrm{O}$ stretching vibrations in monomeric $(\mathbf{\square}) \mathrm{VO}_{x}$ and crystalline $\mathrm{V}_{2} \mathrm{O}_{5}(\mathbf{\bullet}$ 


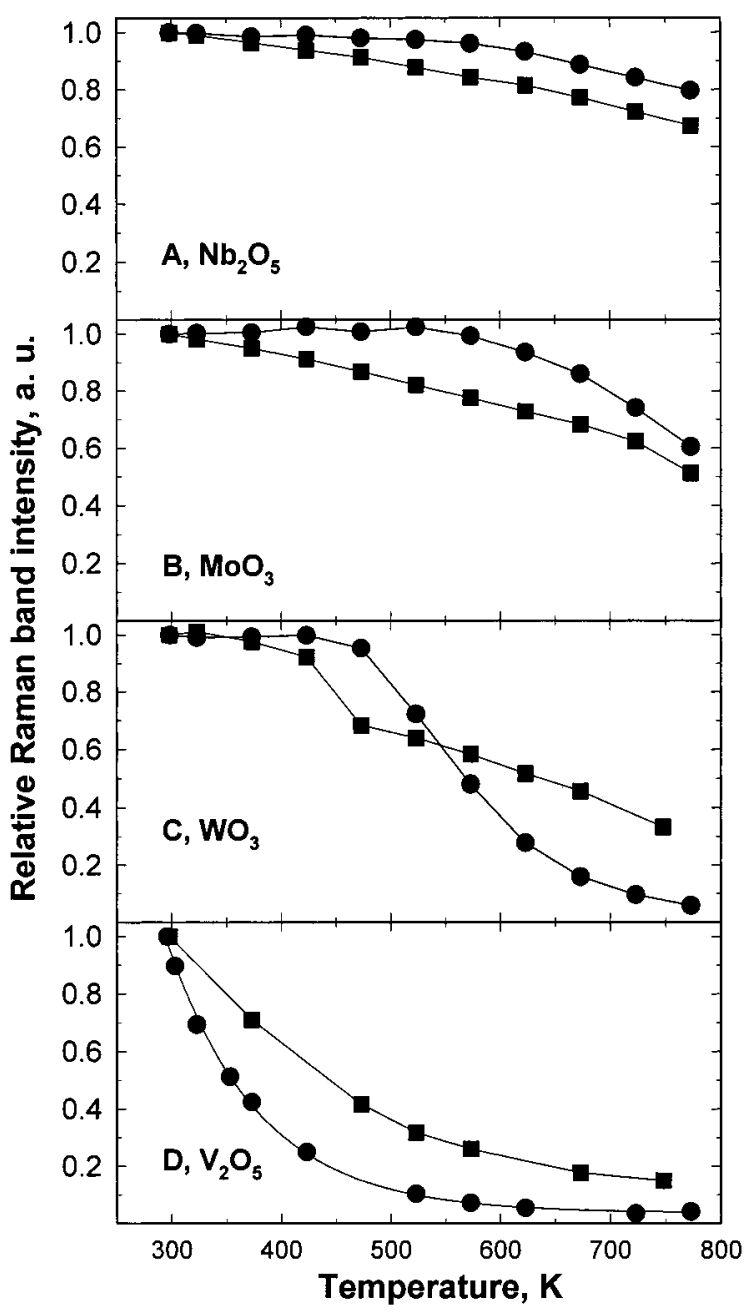

Figure 11. Comparison of the dependence of band intensity for $\mathrm{M}=$ $\mathrm{O}(\mathrm{M}=\mathrm{Nb}, \mathrm{Mo}, \mathrm{W}, \mathrm{V})$ stretching vibrations on temperature determined experimentally and theoretically (eq 5). (A) $\mathrm{Nb}_{2} \mathrm{O}_{5}$; (B) $\mathrm{MoO}_{3}$; (C) $\mathrm{WO}_{3}$; (D) $\mathrm{V}_{2} \mathrm{O}_{5} . \bullet$, experiment; $\mathbf{\square}$, theory.

absorption of the Raman scattered radiation within oxide crystallites for supported oxides.

The effects of temperature on the optical absorbance of oxides have been reported previously in the literature. Detailed studies of the optical absorption of bulk $\mathrm{V}_{2} \mathrm{O}_{5}$ have shown that in the long-wavelength tail of the absorption edge, the absorption coefficient obeys Urbach's rule, ${ }^{31,32} K=K_{0} \exp (-\beta h v / k T)(\beta$ $=0.5)$, whereas in the short wavelength region the absorption spectrum is described by $K h v \propto\left(h v-E_{\mathrm{g}}\right)^{3 / 2}$, the relationship for forbidden direct band-to-band transitions. ${ }^{31,32}$ The dependence of the absorption band edge, $E_{\mathrm{g}}$, on temperature obeyed the relation $E_{\mathrm{g}}=E_{\mathrm{go}}+a T$, where $a=-6.1 \times 10^{-4} \mathrm{eV} / K$, and $E_{\mathrm{g} 0}=2.49 \mathrm{eV}$, and $a=-7.3 \times 10^{-4} \mathrm{eV} / \mathrm{K}$ and $E_{\mathrm{g} 0}=$ 2.54 for parallel and perpendicular polarization, respectively. These values of $E_{\mathrm{g} 0}$ and $a$ agree well with those reported in Table 1. The low-energy tail in the absorption curve has been attributed to electronic defects arising from nonstoichiometry. ${ }^{33-36}$ There appears to be no definitive theoretical explanation for the decrease in the adsorption band gap with increasing temperature but several authors have suggested that it may be due to the degree of nonstoichiometry of $\mathrm{V}_{2} \mathrm{O}_{5} \cdot{ }^{37,38}$ This conclusion is not unreasonable because independent investigations have shown that with increasing temperature, $\mathrm{V}_{2} \mathrm{O}_{5}$ will loose oxygen to form a series of $\mathrm{V}_{n} \mathrm{O}_{m}$ phases, starting with $\mathrm{V}_{3} \mathrm{O}_{7}{ }^{39}$
It is evident from the preceding discussion that the effects of temperature on the intensity of Raman features will become more severe the closer the absorption band edge is to the energy of the laser line and the weaker the $\mathrm{M}-\mathrm{O}$ bonds are in the oxide. Consistent with this, the results presented here show that the influence of temperature on Raman band intensities increases in the order $\mathrm{Nb}_{2} \mathrm{O}_{5}<\mathrm{WO}_{3}<\mathrm{MoO}_{3}<\mathrm{V}_{2} \mathrm{O}_{5}$. This is the same as the order in which the difference between the laser line energy and the absorption band edge decreases, and the $\mathrm{M}-\mathrm{O}$ bond strength decreases. It is also notable that for supported metal oxides, Raman spectra recorded at elevated temperatures will under-represent those species exhibiting moderate to strong optical absorbance at the optical frequency corresponding to the Raman scattered light. This effect has been reported in refs 10 and 13.

Finally, it is appropriate to comment on the relationship of resonance Raman scattering to the phenomenon discussed in this study. In the case of resonance Raman scattering, a very strong enhancement in the Raman signal is observed when the laser frequency coincides with an optical transition. The reason that such an effect is not observed for both bulk and dispersed oxides is that these solids do not exhibit well-defined optical absorbances but, rather, a series of states lying within the band gap between the valence and conduction bands. Coupling of optically excited states to the phonon spectrum is facile in oxides, leading to a rapid dissipation of the energy in the excited state before the Raman process can occur. The absence of resonance Raman effects is supported by the observation that the intensity of the Raman bands at room temperature for oxides exhibiting optical absorption near the laser line (e.g., $\mathrm{V}_{2} \mathrm{O}_{5}$ ) are comparable to those that do not exhibit strong optical absorption near the laser line (e.g., $\mathrm{Nb}_{2} \mathrm{O}_{5}$ ).

\section{Conclusions}

This study demonstrates that the intensity of Raman spectra for bulk and dispersed oxides can depend on the temperature when significant optical absorbance occurs in the frequency range corresponding to the Raman line. Increases in optical absorption with temperature reflect the loss of oxygen and the consequent formation of nonstoichiometric oxides and stoichiometric suboxides. For bulk oxides exhibiting a band edge in the vicinity of the laser frequency, an increase in optical absorption of the oxide leads to a decrease in the sampling depth for Raman spectroscopy decreases and concomitant loss in signal intensity. The closer the absorption band edge of the oxide to the laser frequency and the weaker the metal-oxygen bonds in the oxide, the more severe will be the effects of temperature on the intensity of the Raman spectra. For dispersed metal oxides, the effect of temperature on the Raman spectrum also depends on the proximity of the absorption band to the laser line. If it is close, then the effects of temperature will be similar to those observed for bulk oxides, namely a uniform decrease in Raman band intensity with increasing temperature. However, when the band edge of the sample is far removed from the position of the laser line, then the effects of temperature on Raman band intensity will depend on the optical absorbance of the dispersed species. Species with absorption band edges far from the energy of the laser line will not be strongly affected by temperature, whereas species having band edges close to the energy of the laser line will be affected by temperature. In this latter case, it is proposed that the loss in signal intensity is due to absorption of the Raman scattered photons within the particles where these photons originate. The phenomena described in this study must be taken into account to properly interpret the effects of 
temperature on the Raman spectra of bulk and dispersed oxides. It is also evident that the effects of optical absorption can be minimized by using a laser frequency that is significantly lower than that corresponding to the absorption band edge of the oxide.

Acknowledgment. This work was supported by the Director, Office of Basic Energy Sciences, Chemical Sciences Division, of the U.S. Department of Energy under Contract No. DE-AC0376SF00098.

\section{References and Notes}

(1) Clark, R. J. H.; Hester, R. E. Advances in Infrared and Raman Spectroscopy; Vols. 1-18; J. Wiley; New York; 1975-89.

(2) Delgass, N.; Haller, G.; Kellerman, R.; Lunsford, J. H.; Eds. Spectroscopy in Heterogeneous Catalysis; Academic Press: New York; 1979.

(3) Willis, R. F. Vibrational Spectroscopy of Solids; Springer-Verlag: New York; 1980.

(4) Stencel, J. M. Raman Spectroscopy of Catalysis; Van Nostrand: Rheinhold; New York; 1990.

(5) Grasselli, J. G., Bulkins, B. J., Eds. Analytical Raman Spectroscopy; J. Wiley: New York, 1991

(6) Mestl, G.; Srinivasan, T. K. K. Catal. Rev. Sci-Eng. 1998, 40, 451.

(7) Wachs, I. E.; Chan, S. S. Appl. Surf. Sci. 1984, 20, 181.

(8) Chan, S. S.; Wachs, I. E.; Murrell, L. L.; Wnag, L.; Hall, W. K. J. Phys. Chem. 1984, 88, 5831.

(9) Jehng, J.-M.; Deo, G.; Weckhuysen, B. M.; Wachs, I. E. J. Mol. Catal. A: Chem. 1996, 110, 41.

(10) Xie, S.; Iglesia, E.; Bell, A. T. Langmuir, 2000, 16, 7162.

(11) Payen, E.; Kastelan, S.; Grimblot, J. J. Raman Spectrosc. 1986, $17,233$.

(12) Le Coustumer, L. R.; Taouk, B.; Le Meur, M.; Payen, E.; Guelton, M.; Grimblot, J. J. Phys. Chem. 1988, 92, 1230.

(13) Cristiani, C.; Forzatti, P.; Busca, G. J. Catal. 1989, 116, 586.

(14) Balachandran, V.; Eror, N. G. J. Mater. Sci. Lett. 1982, 1, 374.
(15) Ikeya, T.; Sena, M. J. Non-Cryst. Solids 1988, 105, 243.

(16) Pittman, R. T.; Bell, A. T. J. Phys. Chem. 1993, 97, 12178.

(17) Py, M. A.; Schmid, Ph. E.; Maschke, K. A. Nuovo Cimento B 1977, 38,271

(18) Py, M. A.; Maschke, K. A. Physica B 1981, 105, 370.

(19) Ohwada, K. Spectrochim. Acta 1970, 26, 1035.

(20) Anderson, A. Spectrosc. Lett. 1976, 9, 809.

(21) Abello, L.; Husson, E.; Repelin, Y.; Lucazeau, G. Sprectochim. Acta 1983, 39A, 641

(22) Gao, X.; Bare, S. R.; Weckhuysen, B. M.; Wachs, I. E J. Phys. Chem. 1998, 102, 10842.

(23) Clark, R. J. H., Hester, R. E., Eds. Advances in Infrared and Raman Spectroscopy; Heyden: London, Vol. 6, 1980.

(24) Pines, A. S.; Tannenwald, P. E. Phys. Rev. 1969, 178, 178.

(25) Cowley, R. A. Le J. Phys. 1965, 26, 659.

(26) Kortum, G. Reflectance Spectroscopy-Principles, Methods, Applications; Springer-Verlag: New York; 1969.

(27) Morey, M.; Davidson, A.; Eckert, H.; Stucky, G. Chem. Mater. 1996, $8,486$.

(28) Tran, K.; Hanning-Lee, M. A.; Biswas, A.; Stiegmann, A. E.; Scott,

G. W. J. Am. Chem. Soc. 1995, 117, 2618.

(29) Tran, K.; Stiegmann, A. E.; Scott, G. W. Inorg. Chim Acta, 1996, $243,185$.

(30) Rulkens, R.; Male, J. L.; Terry, K. W.; Olthof, B.; Khodakov, A.; Bell, A. T.; Iglesia, E.; Tilley, T. D. Chem. Mater. 1999, 11, 1966.

(31) Bodo, Z.; Hevesi, I. Phys. Stat. Sol. 1967, 20, K45.

(32) Hevesi, I. Acta Phys. Sci. Hong. 1967, 23, 415.

(33) Dexter, D. L. Suppl. Nuovo Cimento. 1958, 7, 245.

(34) Redfield, D. Phys. Rev. 1963, 130, 916.

(35) Aita, C. R.; Liu, Y.-L.; Kao, M. L.; Hansen, S. D. J. Appl. Phys. 1986, 60, 749.

(36) Benmoussa, M.; Ibnouelghazi, E.; Bennouna, A.; Ameziane, E. L. Thin Solid Films 1995, 265, 22.

(37) Kenny, N.; Kanneworf, C. R.; Whitmore, D. H. J. Phys. Chem. Solids 1966, 27, 1237.

(38) Moshfegh, A. Z.; Ignatiev, A. Thin Solid Films 1991, 198, 251.

(39) Brewer, L.; Ebbinghaus, B. Thermochim. Acta 1988, 129, 49. 